\title{
Annals of Physiotherapy \& Occupational Therapy
}

\section{Do they know us?}

\section{Rod Charlie DR*}

Philippine Academy of Occupational Therapists, Philippines

\section{Editorial}

Volume 1 Issue 1

Received Date: October 01, 2018

Published Date: October 12, 2018

DOI: $10.23880 /$ aphot- 16000103

Occupational Therapists, Inc. Manila, Philippines, Tel: +639178746689; Email:

delosreyes.rodcharlie@yahoo.com

\section{Editorial}

Occupational therapy and physical therapy are two distinct fields in rehabilitation that were developed for a long time already and continue to evolve as the needs and further research on their efficacy to promote change unfolds. However, despite the increasing number of therapists all over the world, there are still confusions between the two professions, and even more alarming, is that in some areas especially in the developing countries, these fields are not yet fully recognized and understood. The question of, "Do they know us?" still exists. Hence, advocacy movements towards awareness and correcting misconceptions is still relevant and will always be relevant as long as therapists continue to pose their worth in the field of health.

\section{What is advocacy?}

Advocacy is an active promotion of a clear idea or cause that promotes change or awareness. It is not merely a revolution due to an existing problem but a spread of principle that a group of people or in this paper, the therapists, wanted to reach the masses. It is a task that is under hands of the therapists that were bestowed to them when they took the oath of being in that profession. It is their duty to make known to the people what they do so that they could help and aid people reach their goals.

\section{How to Advocate?}

There are a lot of ways to advocate. However, there are sustainable and effective ways to do so. It involves a critical strategic planning to create a set of goals, projects and evaluation methods that impact the society. In this paper, some of the essential steps will be discussed and provided with examples that are geared towards the promotion of occupational and physical therapy.
1. The initial step in this endeavor is creating a specific and defined goal or goals. This is done with the realization of the problem of need that warrants attention. In the current issue of the existence of misconceptions and lack of knowledge of some people with occupational and physical therapy, a goal that is measurable could be the increase and active attempts of more people to avail these services due to their realization of need and basic understanding of these professions.

2. The second step would be the identification of the target population. It could be done through surveys, scanning of previous studies or even being with these groups of people. The end point would be the understanding why they are target population, and how can they be affected by the advocacy. In some developing countries, occupational and physical therapy are still confused with psychotherapists or massage therapists due to the nature of closeness with these said fields. Hence, it is really necessary that these people in these countries need advocacy movements so that they can avail correct services to have an appropriate intervention.

3. Gathering of materials and developing a message would proceed after. It may take time and may be under continuous change but it should always be aligned with the specific goal or vision set in the start. It is a good thing that the two professions have the World Federation of Occupational Therapists and World Confederation for Physical Therapy that can provide materials for promotion. Also, with the extensive knowledge of one's profession, a therapist can create materials that are relatable and informing. 
4. After packaging the message, one should mobilize it. It should be shared in a proper and effective way that would enable true change. Mere distribution of fliers or using social media is not enough. There should be active engagement with the target population. The message should be heard and could promote the listeners to be advocates as well. In this step, the group of advocates, now the occupational and physical therapists together with their stakeholders could create networks and alliances with more groups and hopefully the government. Some examples of mobilization are group discussions, needs assessment forums, etc.

5. The last step is the evaluation and monitoring of the advocacy that was started. To properly implement this, one should have clear outcomes. Hence, going back to the start, there should be a clear goal. And for discussion, the example would be increased number of people availing these services then it could be turned into inserting the fields of occupational and physical therapy in the health framework of the nation. This is how the goals are measured and monitored wherein when one is achieved, proceed to the next.

The enumerated steps are basic components of doing an advocacy movement. Creating one is not an easy task even for therapists that are already called professionals. It takes time and effort but it is a professional responsibility. Even advocacy could be done in simple ways like talking about it, or sharing what is occupational and physical therapy with friends, there is power in numbers so it is highly encouraged for therapists to come together and create advocacy projects so that next time therapists will ask, "Do you know us?" people will easily be able to explain what occupational and physical therapy could do for and with them. 